\title{
Genomic and physiological responses to strong selective pressure during late organogenesis: few gene expression changes found despite striking morphological differences
}

\author{
Goran Bozinovic ${ }^{1,5^{*}}$, Tim L Sit ${ }^{2}$, Richard Di Giulio ${ }^{3}$, Lauren F Wills ${ }^{3}$ and Marjorie F Oleksiak ${ }^{1,4}$
}

\begin{abstract}
Background: Adaptations to a new environment, such as a polluted one, often involve large modifications of the existing phenotypes. Changes in gene expression and regulation during critical developmental stages may explain these phenotypic changes. Embryos from a population of the teleost fish, Fundulus heteroclitus, inhabiting a clean estuary do not survive when exposed to sediment extract from a site highly contaminated with polycyclic aromatic hydrocarbons (PAHs) while embryos derived from a population inhabiting a PAH polluted estuary are remarkably resistant to the polluted sediment extract. We exposed embryos from these two populations to surrogate model PAHs and analyzed changes in gene expression, morphology, and cardiac physiology in order to better understand sensitivity and adaptive resistance mechanisms mediating PAH exposure during development.
\end{abstract}

Results: The synergistic effects of two model PAHs, an aryl hydrocarbon receptor (AHR) agonist ( $\beta$-naphthoflavone) and a cytochrome P4501A (CYP1A) inhibitor (a-naphthoflavone), caused significant developmental delays, impaired cardiac function, severe morphological alterations and failure to hatch, leading to the deaths of reference embryos; resistant embryos were mostly unaffected. Unexpectedly, patterns of gene expression among normal and moderately deformed embryos were similar, and only severely deformed embryos showed a contrasting pattern of gene expression. Given the drastic morphological differences between reference and resistant embryos, a surprisingly low percentage of genes, $2.24 \%$ of 6,754 analyzed, show statistically significant differences in transcript levels during late organogenesis between the two embryo populations.

Conclusions: Our study demonstrates important contrasts in responses between reference and resistant natural embryo populations to synergistic effects of surrogate model PAHs that may be important in adaptive mechanisms mediating PAH effects during fish embryo development. These results suggest that statistically significant changes in gene expression of relatively few genes contribute to the phenotypic changes and large morphological differences exhibited by reference and resistant populations upon exposure to PAH pollutants. By correlating cardiac physiology and morphology with changes in gene expression patterns of reference and resistant embryos, we provide additional evidence for acquired resistance among embryos whose parents live at heavily contaminated sites.

Keywords: Development, Genomics, Embryos, Adaptation, Evolution, Fish, Transcriptomics

\footnotetext{
*Correspondence: gbozinovic@ucsd.edu

'Department of Environmental and Molecular Toxicology, North Carolina

State University, Box 7633, Raleigh, NC 27695-7633, USA

${ }^{5}$ Current Address: Division of Biological Sciences, University of California at

San Diego, HSS 1145G, 9500 Gilman Drive, La Jolla, CA 92093, USA

Full list of author information is available at the end of the article
} 


\section{Background}

We studied genomic responses to the effects of chemicals routinely found in complex mixtures of pollutants present in the urban estuaries during late organogenesis of Fundulus heteroclitus embryos. Natural Fundulus populations are one of the few studied fish species in North America that have established resistant populations in highly contaminated urban estuaries [1]. Changes in gene expression, coupled with biochemical, physiological, and behavioral alterations play a critical role in adaptation to environmental stress. Our study explores the ways natural populations may have adapted to local polluted environments by correlating their genomic responses to changes in morphology and physiology during development.

Fundulus heteroclitus, a small, abundant, salt marsh fish that inhabits the eastern North American coast, has become a leading model in environmental biology. Natural Fundulus populations can tolerate a variety of environmental conditions and display an array of adaptations to both natural and anthropogenic variables in their ecosystems. F. heteroclitus is an ecologically important and genetically diverse model to elucidate pollution effects and genotype-environment interactions within and among natural populations.

$F$. heteroclitus is one of the few studied species in North America living in the highly polluted urban estuaries that has shown resistance to pollutants among both adults and embryos [2-5]. Multiple Fundulus populations inhabit and have adapted to heavily contaminated urban estuaries $[4,6,7]$ which contain persistent and bioaccumulative chemicals that are toxic to early fish development $[2,4]$. Acute and chronic exposure of Fundulus embryos to chemicals present in the polluted sites can lead to functional deficit, growth retardation, malformation, and even death $[3,4,6]$.

Resistance to the lethal effects of pollution has been reported in $F$. heteroclitus embryos from the Elizabeth River, VA, a Superfund site contaminated with creosote, a mixture of polycyclic aromatic hydrocarbons (PAHs) $[7,8]$. PAHs are petroleum products created by the combustion of organic materials that originate from both natural and anthropogenic sources. They have been found at 600 of 1,430 National Priority List sites, and as a group they are ranked number eight on the 2007 Comprehensive Environmental Response, Compensation, and Liability Act (CERCLA) priority list of hazardous substances $[9,10]$. These chemicals pose a significant risk to human and animal health due to their carcinogenic properties; research in aquatic organisms has described their equally damaging role as teratogens $[11,12]$. The PAH concentrations in the sediments collected at the Elizabeth River site are some of the highest in the world [8], averaging 200-400 ug/g. These PAHs include carcinogens, such as benzo(a)pyrene (BaP), chrysene, and dibenzo(a,h) anthracene $[13,14]$.
Cardiovascular malformations, resulting in significantly higher mortality rates, are well documented in fishes exposed to PAH mixtures [12,15-18]. Some of these effects are thought to be mediated by the aryl hydrocarbon receptor (AHR) [15,19-22]. Studies of cardiovascular effects using model PAHs show synergistic interaction between PAH-type AHR agonists and CYP1A-inhibitors. Typically, the AHR pathway is induced by PAHs and activates expression of CYP1A [23]. In $F$. heteroclitus, embryos exposed to the PAH-type AHR agonist $\beta$-naphthoflavone (BNF) and the CYP1A inhibitor $\alpha$-naphthoflavone (ANF) had decreased levels of CYP1A activity and a synergistic increase in the occurrence of cardiac deformities as measured by heart elongation and pericardial edema [17]. BNF and ANF are synthetic flavonoids commonly used as surrogate model PAHs: BNF acts as an AHR agonist and ANF acts as a reversible competitive CYP1A inhibitor that can bind to either the active site or the ferric heme [24-26]. Agonists and inhibitors often co-occur in typical PAH mixtures, and although the current risk assessments of PAHs assumes an additive model of PAH toxicity, this synergy may be an important outcome for risks posed by PAH-exposure.

Fundulus gene-environment interaction studies include both natural and anthropogenic environmental effects on anatomy, physiology, development, molecular biology, and recently a genome [27-30]. Consequently, natural Fundulus populations have become a preferred model to study teleost evolutionary adaptations to a range of selective pressures. The effects of pollution on Fundulus' genetics have been studied in some populations [1,31-36]; however, little is known about functionally important variation in embryo gene expression underlying resistance mechanisms. To explore the response differences between reference and resistant populations to pollution at the genomic and molecular level, we exposed embryos of parents from King's Creek, VA (reference) and Elizabeth River, VA (resistant) to a defined surrogate mixture of PAH pollutants, which are routinely found in the contaminated sediment extracts. By correlating multiple phenotypes to changes in gene expression patterns, we provide additional evidence for acquired resistance among embryos whose parents live at heavily contaminated sites.

We chose to study late organogenesis of Fundulus development due to its high metabolic activity, observable phenotypes, and likely cumulative effect of chemical exposure on organ anatomy and physiology. Hence, we compare survival rates, time-to-stage, morphology, cardiac physiology, and gene expression profiles of individual Fundulus embryos from PAH-reference and resistant natural populations exposed to a mixture of two model PAHs at environmentally relevant concentrations [14]. Our study demonstrates important contrasts in responses between reference and resistant embryos to synergistic 
effects of this defined mixture of pollutants. Altered phenotypes and significant changes in gene expression reveal evidence for acquired resistance among embryos from heavily contaminated sites. However, while the phenotypic alterations are comparable to embryo responses to polluted sediment extracts (unpublished data), a surprisingly few number of significant genes reflect differences in severity of synergistic effects between the two embryo populations.

\section{Results}

\section{Embryo survival, hatching success, and developmental delays}

During Fundulus late organogenesis (stage 31), survival rates were not significantly different between populations for all treatment groups (2-way ANOVA, $\mathrm{p}=0.97$; Figure 1A. The lowest survival was noted among reference embryos treated with low ANF (50 ug/L, 71.1\% 土10.7), while the highest survival rate was among resistant embryos $(90 \% \pm 5.0)$ treated with BNF $(1 \mathrm{ug} / \mathrm{L})+$ high ANF $(100 \mathrm{ug} / \mathrm{L})$. All of the embryos that hatched survived to the final embryonic stage characterized by complete yolk consumption and free-swimming larvae.

At stage 40, all of the reference embryos failed to hatch and did not survive either the lower or higher ANF/BNF co-exposure (Figure 1B). A 2-way ANOVA $(\mathrm{p}<0.05)$ indicated significant differences in hatching success among embryo treatment groups. Bonferroni's post-test revealed significant differences between reference and resistant embryos for both BNF + low ANF $(\mathrm{p}<0.001, \mathrm{t}=6.74)$, and BNF + high ANF $(\mathrm{p}<0.001$, $\mathrm{t}=6.12$ ) treatment groups.

Although most of the embryos reached stage 31 within the expected time period, significant developmental delays were noted among reference embryos exposed to both low and high ANF + BNF treatments (2-way ANOVA, $\mathrm{P}<0.01$; Figure $1 \mathrm{C}$ ). Bonferroni post-test analysis of developmental stage at 144-150 hours post fertilization revealed
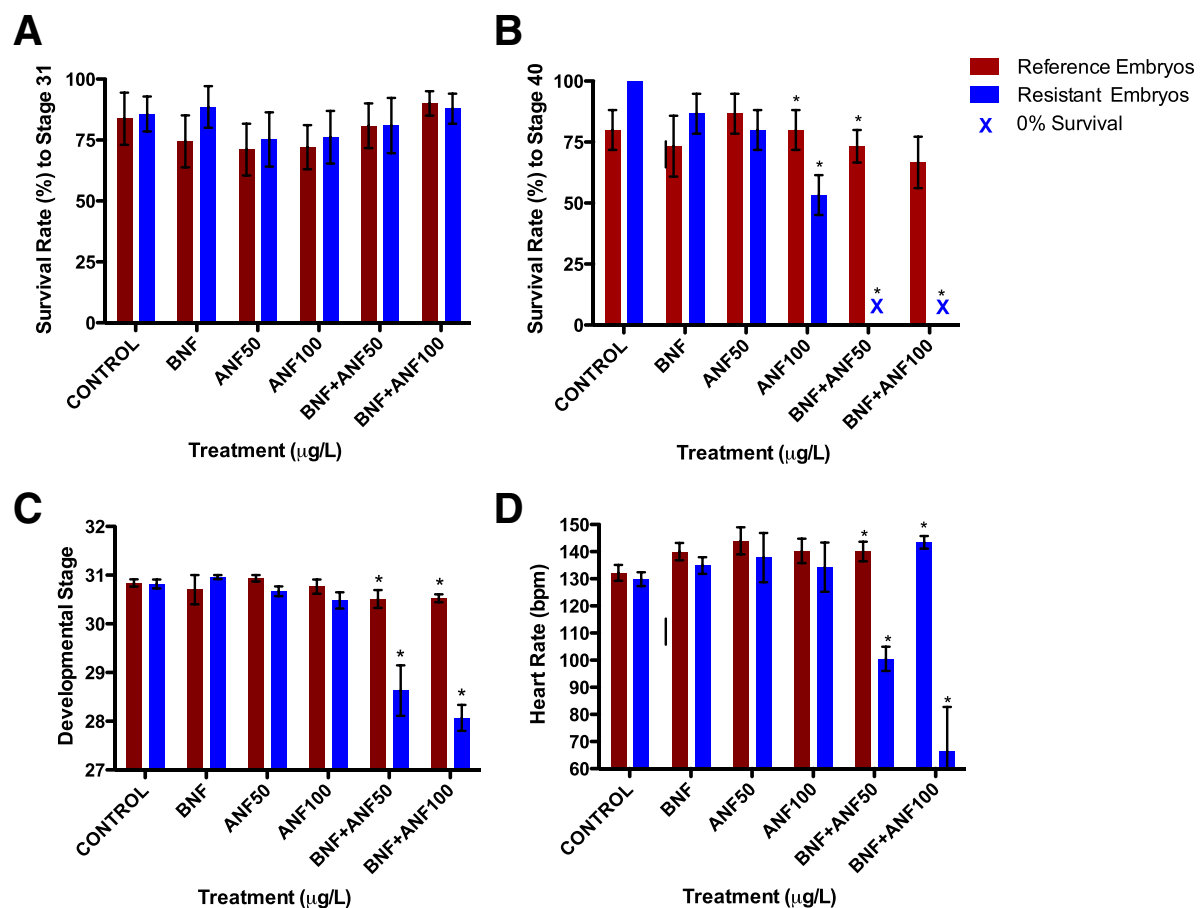

Figure 1 Survival, developmental delays, and heart rates of reference (Kings' Creek - blue) and resistant (Elizabeth River - red) Fundulus embryos. A) Embryo survival (2-way ANOVA, $p=0.97$ ) among five treatment groups within reference and resistant embryo populations at developmental stage 31 (late organogenesis). Sensitive and resistant embryo's survival is not affected by any treatment at the stage 31. B) Hatching success and survival to stage 40 ( 2 -way ANOVA, $\mathrm{p}<0.01)$ among reference and resistant embryos. The cumulative effects in both combined treatments have significant effect among sensitive embryos, as they fail to hatch, while the resistant embryo survival is largely unaffected. C) Development among control and five treatment groups of reference and resistant embryos at 144-150 hours post-fertilization: although most of the embryos reached stage 31 within the expected time period, significant developmental delays were noted among reference embryos exposed to both low and high ANF + BNF treatments (2-way ANOVA, P <0.01). Reference embryos were significantly delayed (on average 3 developmental stages, $\sim 40 \mathrm{~h}$ ) relative to resistant embryos in both combined treatments (Bonferroni post-test analysis, $p<0.01$ ), while embryo development in discrete treatments did not significantly differ. D) Embryo heart rates: reference and resistant embryos' heart rates during stage 31: significant bradycardia (2-way ANOVA, $p<0.01$ ) were noted among reference embryos at both lower $(p<0.04 ; t=4.12)$ and higher $(p<0.05 ; t=8.03)$ BNF/ANF dose exposures relative to resistant embryos. Asterisks $\left(^{*}\right)$ represent statistically significant within-treatment differences (Student's t-test, $\mathrm{p}<0.05$ ) between Elizabeth River (resistant) and King's Creek (reference) embryos. 
significant differences among reference embryos and between reference and resistant embryos in both combined treatments $(\mathrm{p}<0.01)$, while embryo development in discrete treatments did not significantly differ. Reference embryos were on average 3 stages behind (approximately 40 hours) when compared to resistant embryos from the same combined treatment group (2-tailed t-test, $\mathrm{p}<0.01)$.

\section{Heart rate}

Heart rate results at stage 31 mirrored developmental delay data: significantly slower heart rates (bradycardia; 2 way-ANOVA, $\mathrm{p}<0.01$; Figure 1D) were noted among sensitive embryos in combined treatment groups. Bonferroni post-test revealed statistically significant differences in reference embryos exposed to BNF + low ANF $(100.5 \pm 10.1$ bpm; $\mathrm{p}<0.01 ; \mathrm{t}=4.12)$ and $\mathrm{BNF}+$ high ANF $(66.3 \pm 36.8$ bpm; $\mathrm{p}<0.01 ; \mathrm{t}=8.03)$ when compared to all other treatment groups in both reference and resistant embryo populations.

\section{Embryo morphology}

Severe and extreme morphological abnormalities were noted among all reference embryos in combined treatment groups (Figure 2B). These deformities included pericardial edema, hemorrhaging, cranio-facial malformations, tail shortening and bleeding, and general loss of pigment (Figure 2A). The most severely affected reference embryos in BNF + high ANF treatments were characterized by overall smaller size, loss of cranial ridges, cranium size reduction with diminished eye distance, aggregation and reduction of body pigmentation and hemorrhaging throughout the entire caudal region; these morphologies were only observed among the reference embryos in higher co-exposure treatment group. Their hearts (score $>4$ on a scale of $1-5$ where 1 indicates no deformity and 5 indicates extreme deformity) failed to differentiate, resulting in a "tube-heart" structure, which appears as a barely-visible long tube through which transparent fluid slowly trickles (instead of 2 fullyformed round chambers with red blood forcefully pumping from the atrium into a ventricle, as seen in the control embryos). The average score for the BNF + low ANF treatment group was 3.7 and was 4.6 for the BNF + high ANF treatment group. Any embryo with a score $>3$ failed to hatch. Statistical differences (Bonferroni post-test, $\mathrm{p}<0.05)$ were noted between reference and resistant embryos in 4/6 treatments, with reference embryos being significantly more deformed at low ANF $(\mathrm{p}<0.05 ; \mathrm{t}=2.91)$, high ANF $(\mathrm{p}<0.01 ; \mathrm{t}=5.827), \mathrm{BNF}+$ low ANF $(\mathrm{p}<0.01$, $\mathrm{t}=9.71)$, and BNF + high ANF $(\mathrm{p}<0.01, \mathrm{t}=13.11)$.

The relationship between heart rates and in vivo morphological deformities is presented in Figure 2C-E. Combined data of reference and resistant embryos show a strong correlation between heart rate and morphology $\left(R^{2}=0.78\right.$; Figure $\left.2 E\right)$ : as the deformities progress among reference embryos throughout treatments, the bradycardia becomes more pronounced, reflecting the impaired heart function among reference embryos. A similar trend is apparent among reference embryos only (Figure 2D) showing the strong correlation $\left(R^{2}=0.82\right)$ between the progression of deformities and bradycardia among reference embryos. However, this is not the case for resistant embryos (Figure 2E), as progression of deformities does not correlate with the decrease in heart rate $\left(R^{2}=0.044\right)$. Moreover, the resistant embryos show a slight increase in heart rates (tachycardia) as deformities progress. Notably, none of the exposed resistant embryos were scored higher than 3 (moderate deformities) while all of the reference embryos in co-exposures with BNF and ANF were scored between 4 (severe deformities) and 5 (extreme deformities).

\section{Gene expression}

Of the 6,754 genes analyzed for altered expression patterns, expression of 151 genes $(2.24 \%)$ is significantly different (mixed model ANOVA, $\mathrm{p}<0.01$; Figure 3A). The combined effect of population and treatment analysis reveals 73 significant genes (Figure 4A). Expression of 52 genes is significantly different due to the effect of treatment alone (Figure 4B), while 26 genes are differentially expressed due to differences between reference and resistant embryo populations (Figure $4 \mathrm{C}$ ). We found no significant genes when a False Discovery Rate (FDR) correction is applied at $\mathrm{p}<0.05$.

Expression of 105 genes (1.6\%) is significantly different (mixed model ANOVA, $\mathrm{p}<0.01$ ) due to the effects of embryo morphology among reference and resistant embryos (Figure 3B). While gene expression appears similar among embryos scored for no deformities (index 1), mild (index 2) and moderate (index 3), the most differences in gene expression patterns are among severely deformed (index 4) and extremely deformed (index 5) embryos. Notably, all of the reference embryos exposed to $\mathrm{BNF}+$ low ANF and BNF + high ANF were found to be either severely or extremely deformed, while none of the resistant embryos were found to be more than moderately deformed in any treatment.

\section{Discussion}

Increased mortality rates among adults and embryos, decreased fecundity, and impairment of physiological performances are likely effects of chronic exposure to pollution among populations [37-40]. Such effects may lead to a decrease in effective population size and genetic variability [18]. However, individual responses vary, and while some individuals are sensitive to the pollutants, others survive and reproduce, therefore establishing resistant 


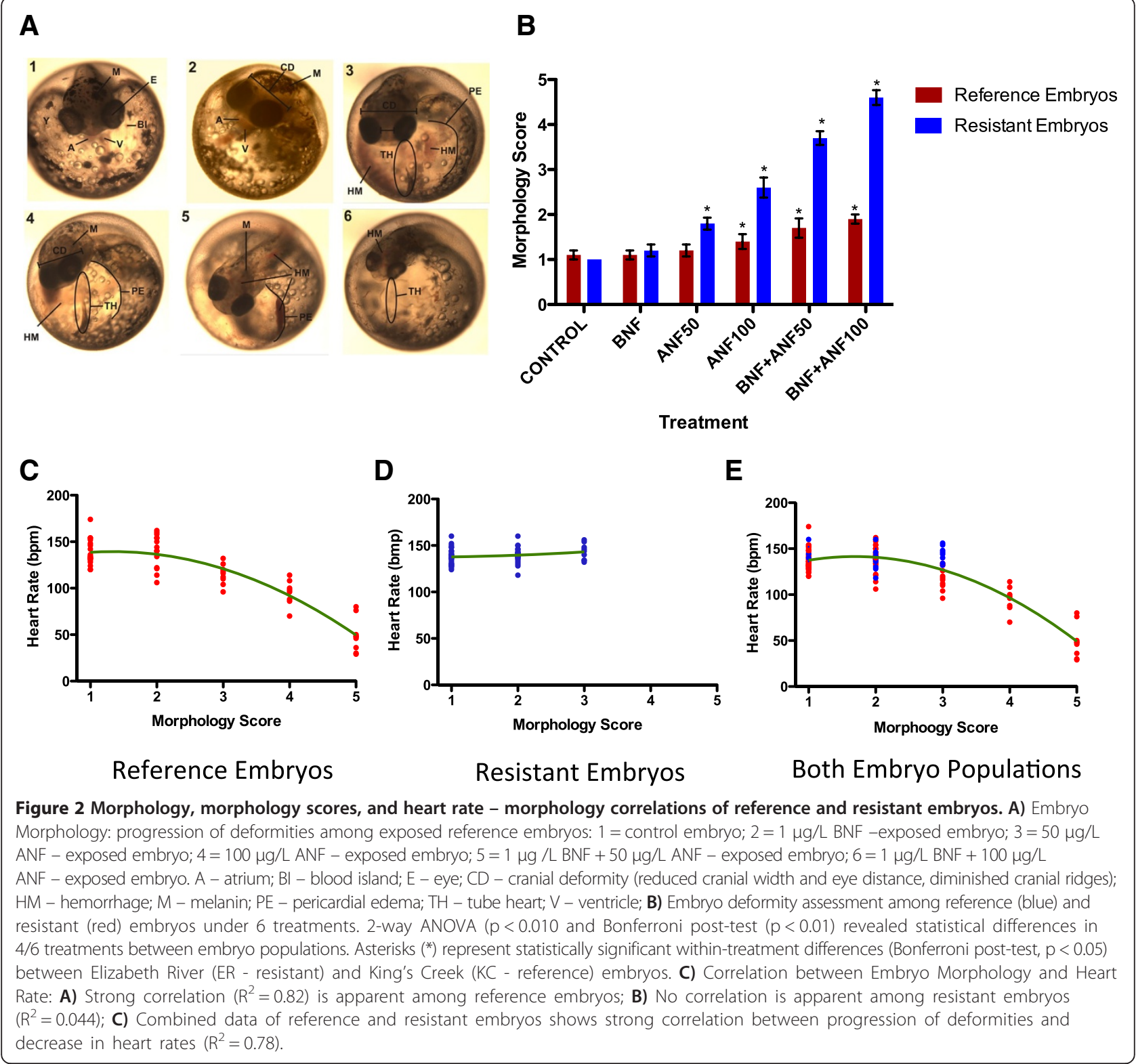

populations. This acquired resistance is associated with fitness costs so that resistance genes are rarely fixed in natural populations [41]; counterbalancing selection pressure decreases the frequency of resistance genes in the absence of inducer, such as a chemical pollutant.

Embryos are highly sensitive to pollution and exposure to contaminated water and sediments can result in altered development and growth and can affect survival. When exposed to highly polluted sediment extracts, F. heteroclitus embryos from reference sites show significantly higher numbers of developmental abnormalities and do not survive, while most of the embryos from polluted sites are resistant and develop normally [3,4,6,7]. What changes contribute to this resistance? Adaptation to a new environment, such as a polluted one, often involves large modifications of the previous phenotype(s) and changes in gene expression and regulation during critical developmental stages may explain these phenotypic changes. Notably, altered gene regulation can affect development, resulting in different morphological or physiological characteristics [42] that are potentially critical for developing resistance.

\section{Differences in survival and development between reference and resistant embryos}

Our study demonstrates important differences between reference and resistant embryo responses during one distinct developmental stage (late organogenesis) to a 


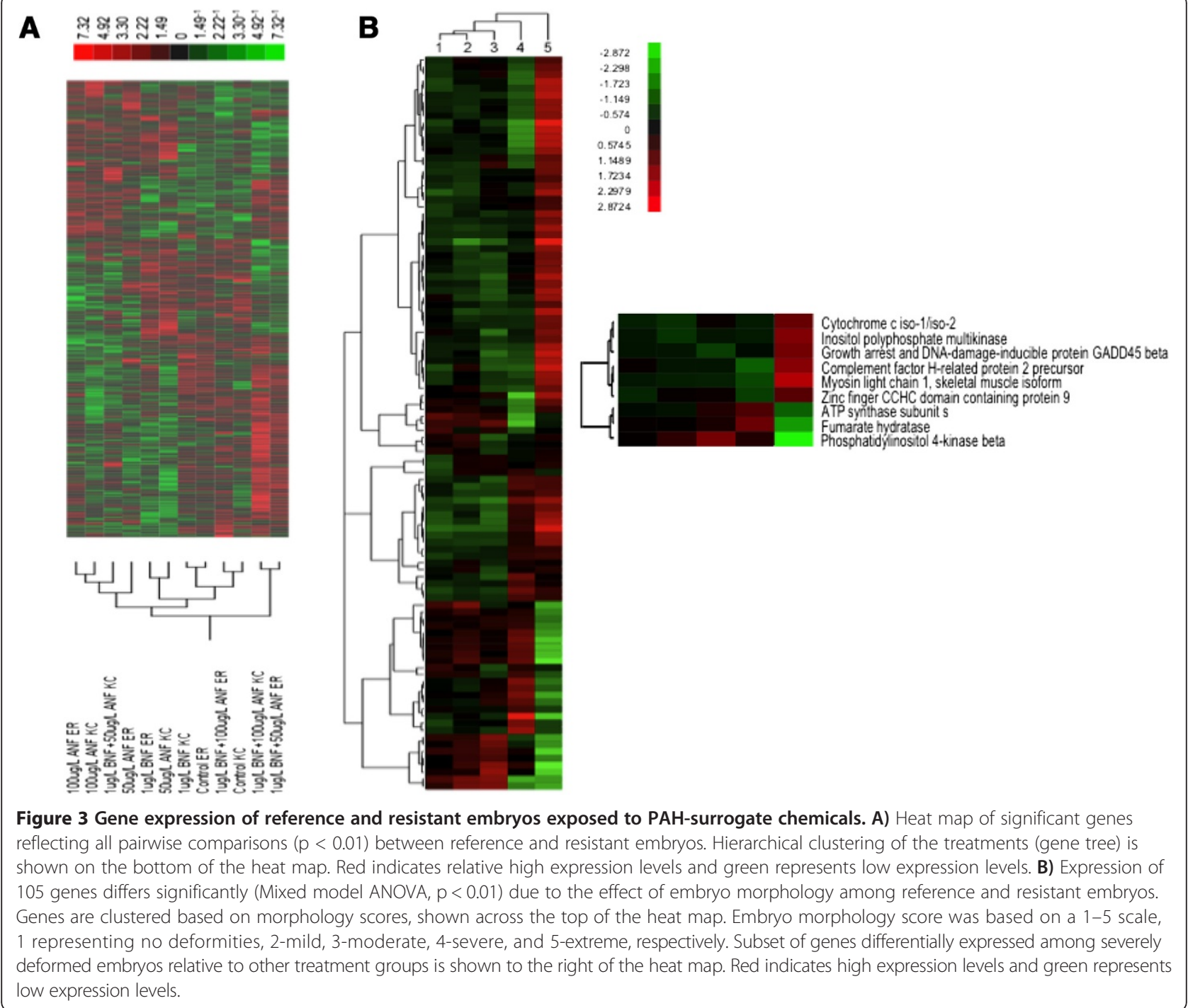

defined mixture of pollutants found in the sediment extracts. We exposed reference and resistant embryos to surrogate model PAHs to better understand physiological, morphological, and gene expression changes underlying development in a polluted environment. By correlating multiple phenotypes to changes in gene expression patterns, we provide additional evidence for acquired resistance among embryos whose parents live at heavily contaminated sites.

Combined treatments of $\beta$-naphthoflavone (BNF) and $\alpha$-naphthoflavone (ANF) were lethal to the reference embryos, while the resistant embryos were largely unaffected: all of the reference embryos failed to hatch and died, while $70 \%$ of the resistant embryos reached the free-swimming larval stage (Figure 1A-B). In all of the phenotypes assessed - survival, developmental delays, cardiac physiology (heart rate), and embryo morphology, the reference embryos were significantly more affected than the resistant embryos: while most treatments caused very little effect on development of resistant embryos, the same exposures caused significant developmental delays, impaired cardiac function, severe morphological alterations and failure to hatch, ultimately causing the death of reference embryos.

Development of reference embryos was significantly delayed among reference embryos (Figure 1C) in the high ANF exposures and both BNF-ANF co-exposures, indicating embryotoxic effects of ANF alone $[25,26]$ and in synergy with BNF. On average, reference embryos lagged almost two days (3 stages, approximately 40 hours) behind resistant embryos given the same exposure. Importantly, exposed resistant embryos developed within the expected time period of both resistant and reference control embryos. 


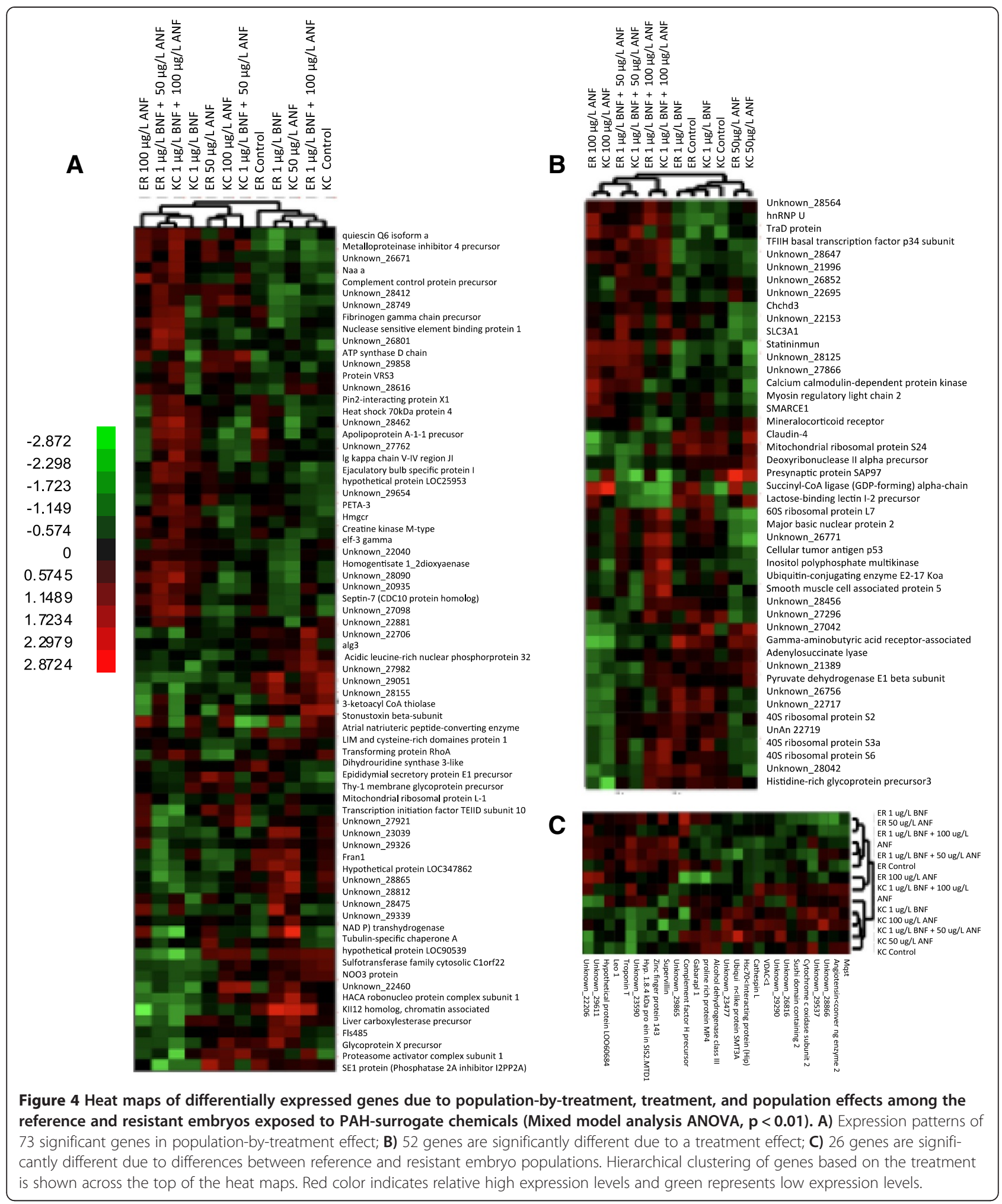

Effects of pollutants on morphology, cardiac anatomy, and physiology on reference and resistant embryos Prior to hatching, reference embryos became severely and/or extremely deformed (Figures $2 \mathrm{~A}$ and $2 \mathrm{~B}$ ), resulting in altered physiology evident by impaired cardiac performance (Figure 1D) and failure to hatch. Although the average heart rate increased slightly among co-exposed resistant embryos, the overall cardiac function did not 
statistically differ between reference and resistant control embryos. We noted the most profound abnormalities in cardiac morphology among reference embryos co-exposed to BNF and ANF: the heart chambers of these embryos failed to differentiate and ultimately resembled elongated transparent tubes ("tube hearts") with very limited contracting ability. We observed significant bradycardia among reference embryos coexposed to BNF and ANF when compared to control embryos of both populations and resistant embryos exposed to the same co-exposures. Other deformities included pericardial edema, severe hemorrhaging, tail shortening, cranio-facial shrinkage, reduced eye distance, and gross loss of pigmentation (Figure 2A). In a few cases, the extreme deformities among reference embryos made identifying structures difficult. In contrast, none of the resistant embryos co-exposed to BNF and ANF were more than moderately deformed. Most (95\%) of the resistant embryos developed fully differentiated heart chambers, capable of delivering blood throughout the embryo. Abnormal morphologies among resistant embryos included slight craniofacial alterations, loss of pigment, mild to moderate pericardial edema, and tail hemorrhaging. Importantly, overall cardiac function of exposed resistant embryos was not affected and did not significantly differ from both reference and resistant control embryos.

We report a strong correlation (82\%) between the severity of morphological deformities and cardiac physiology (Figure 2C-E) among reference embryos. As heart rates significantly decrease and become inefficient in delivering blood to the tissues due to BNF-ANF co-exposures, reference embryos become severely and extremely deformed. Their malformed hearts are unable to support development and embryogenesis ceases before hatching. Such is not the case among resistant embryos, and there is no relationship between the morphology score and cardiac function: heart rates remain unaffected in all resistant embryo treatment groups, demonstrating the ability of resistant embryos to cope with the synergistic effects of BNF-ANF co-exposure.

\section{Gene expression differences between reference and resistant embryos}

Among the differentially expressed genes in embryos from Elizabeth River and King's Creek, expression of 52 genes differs significantly due to treatment alone (Figure 4B), and hierarchical clustering of these genes groups most treatments of reference and resistant embryos together. Expression of 26 genes differs significantly because of differences between reference and resistant embryo populations (Figure 4C). Although our previous comparison of five independent Fundulus populations using the same arrays revealed 30 genes that significantly differ between
King's Creek and Elizabeth River embryos at stage 31 [43], there is no gene overlap with this data. This lack of overlap may reflect the fact that the current comparison examined embryos treated with PAHs while the previous experiment examined untreated embryos collected from parents from King's Creek and the Elizabeth River. Some of the changes in gene expression noted in our present study may be simply due to changes in embryo morphology due to specific chemical exposures, which do not represent other pollutants present in the complex mixtures found in heavily contaminated sites. Also, the spatial and temporal variation associated with chemical exposure among natural populations in the wild may contribute to changes in gene expression not observed in our study.

Expression of 72 genes differs significantly due to the treatment-by-population interaction (Figure 4A). These expression patterns reveal similarities between reference embryos exposed to the higher synergy treatment and resistant embryos exposed to the lower synergy treatment. Interestingly, resistant embryos treated with the highest co-exposure of BNF and ANF group with reference and resistant controls and reference embryos exposed to low ANF, while exposure to BNF alone does not seem to be a determining factor in the cluster analysis.

There is a striking relationship between the morphology score and differential expression of genes (Figure 3B). As synergistic treatment concentrations increase among reference embryos, the severity of deformities observed among embryos increases, causing significant overall reduction in embryo size, bradycardia, disproportional size reduction of cranium including diminished distance between eyes, complete loss of cranial ridges, reduction of eye and body pigment, hemorrhaging along the entire shortened caudal region, cardiac edema, and complete loss of cardiac muscle integrity characterized by the absence of heart chambers and formation of a thin-walled, translucent "tube heart". Expression patterns of genes that correlate with morphology are similar among normal to moderately deformed embryos (1-3 on morphology score scale), while severely deformed embryos (score of 4) show different patterns of gene expression. Gene expression differences become more pronounced between extremely deformed embryos when compared to normal to moderately deformed and severely deformed embryos. Importantly, only reference embryos were scored $>3$ in both lower and higher BNF-ANF co-exposure treatments, providing further evidence of PAH-resistance in the Elizabeth River (resistant) embryo population.

Several genes listed in Table 1, whose expression is correlated with observed morphological abnormalities, are known to play an important role during organogenesis. Although most differences in expression are between 
Table 1 Subset of embryogenesis-related genes whose expression significantly differs between reference (King's Creek) and resistant (Elizabeth River) Fundulus heteroclitus embryos (Mixed model ANOVA, $p<0.01$ ) during late organogenesis stage due to the effect of embryo morphology

\begin{tabular}{|c|c|c|c|}
\hline Gene & Fold diff. & Effect & Ref \\
\hline Cytochrome C oxidase iso-1/iso-2 & 1.51 & Libman-Sacks endocarditis and antiphospholipid syndrome (aPLs) & {$[44,45]$} \\
\hline Complement factor H-related protein 2 & 1.43 & Libman-Sacks endocarditis and antiphospholipid syndrome (aPLs) & {$[44,45]$} \\
\hline Myosin light chain (ELC / RLC) & $1.94 / 1.3$ & $\begin{array}{l}\text { Increase in cardiomyocyte size and number, resulting in a larger ventricular } \\
\text { chamber volume/reduction in size and number of cardiomyocytes }\end{array}$ & {$[48,49]$} \\
\hline ATP synthase subunit $S$ & 1.47 & Cellular ATP synthesis; depletion of the cellular ATP pool during ischemia & {$[46,50]$} \\
\hline GADD45 beta & 1.56 & Cell-cycle control; Somitogenesis abnormalities & {$[47]$} \\
\hline Inositol polyphosphate multikinase (IPMK) & 1.66 & mRNA export, transcriptional regulation, and chromatin remodeling & {$[51]$} \\
\hline Phosphatidylinositol phosphate kinase 4 (PIPK) beta & 2.25 & $\begin{array}{l}\text { Mouse embryo brain expression (cerebral ventricular and mantle zones) } \\
\text { during normal development; postnatal brain gray matter expression }\end{array}$ & {$[47]$} \\
\hline Fumarate hydratase (fumarase) & 1.77 & $\begin{array}{l}\text { Severe neurologic fetal brain abnormalities, poor feeding, failure to thrive; } \\
\text { hypotonia, severe mental retardation, unusual facial features, brain } \\
\text { malformation, epileptic seizures }\end{array}$ & {$[52,53]$} \\
\hline
\end{tabular}

The expression pattern of genes for each morphology score group is presented in Figure $3 \mathrm{~b}$. While gene expression appears similar among embryos scored for no deformities (score 1), mild (score 2) and moderate (score 3), most differences in gene expression patterns are among severely deformed (score 4) and extremely deformed (score 5) embryos. Notably, all of the reference embryos co-exposed to ANF and BNF were either severely or extremely deformed, while none of the resistant embryos were found to be more than moderately deformed in any treatment.

1.4-2.3 fold, relatively small changes in transcript levels may contribute to the morphological and physiological alterations observed among developing embryos. For example, cytochrome $\mathrm{C}$ oxidase iso-1/iso- 2 and complement factor H-related protein 2 have 1.51 fold and 1.43 fold higher transcript levels, respectively, among severely deformed reference embryos in BNF + high ANF treatment group. Both genes are linked to cardiovascular deformities of Libman-Sacks endocarditis and antiphospholipid syndrome (aPLs), marked by mitral and aortic valve lesions. Such abnormalities can cause severe valvular insufficiency, infective endocarditis, stroke [44] and cerebrovascular complications [45]. We noted severe morphological alterations in cardiac tissue in the form of a "tube heart" [28], with significant bradycardia among reference embryos coexposed to BNF and ANF, suggesting that differences in expression levels of these two genes among both reference and resistant embryo populations may contribute to their cardiac deformities. Myosin light chain isoform 1 (ELC/ RLC) and growth arrest and DNA damage-inducible protein GADD45 beta gene are upregulated ( $>7.3$ fold and 3.3 fold, respectively) in severely deformed reference embryos relative to all other treatment groups in both embryo populations (Figure 3B). ELC/RLC overexpression leads to increase in cardiomyocyte size and number resulting in large ventricular chamber volume [46]. Relatively higher expression of these genes may explain severe cardiac abnormalities observed in reference embryos caused by synergistic effect of BNF and ANF in BNF + high ANF treatment group. Moreover, both knockdown and over expression of GADD45 beta genes cause somite defects with different consequences for marker gene expression, suggesting that regulated expression of GADD45 beta genes in the anterior PSM is required for somite segmentation [47]. Overexpression ( $>3.3$ fold; Figure 3B) of GADD45 in severely deformed reference embryos may contribute to synergistic effects if $\mathrm{BNF}+$ high ANF treatment and contribute to skeleto-muscular abnormalities linked to heart abnormalities during late embryogenesis.

Several other genes whose significant changes in expression correlate to morphology are implicated in metabolism and CNS development. The ATP synthase subunit S gene, which is $>4$ fold overexpressed in severely deformed reference embryos relative to moderately-deformed reference embryos (Figure 3B) is a critical enzyme in the cell's energetic pathways, producing the majority of cellular ATP and energetics of the heart which are integrally involved in the causes and phenotypes of heart failure [54,55]. Inositol polyphosphate multikinase (IPMK) plays a critical role in nuclear functions including mRNA export, transcriptional regulation, and chromatin remodeling. Ipk-2-deficient mice die around embryonic day 9.5 with multiple morphological defects, including abnormal folding of the neural tube [51]. IPMK displays a similar overexpression pattern as ELC/RLC and GADD45 in severely deformed reference embryos, likely contributing to observed severe morphological abnormalities among reference embryos exposed to ANF + high BNF treatment.

Notably, significantly lower expression of two genes among reference embryos exposed to BNF + high ANF treatment may contribute to severe morphological deformities. Phosphatidylinositol phosphate kinase 4 (PIPK) beta, which is expressed in the mouse embryo brain (cerebral ventricular and mantle zones), plays a role in the formation 
of cerebral ventricular and mantle zones and gray matter during normal development [47]. Deficiency in fumarate hydratase (fumarase), a gene expressed in human fetal tissues [56] is linked to a fetal brain and severe neurologic abnormalities, poor feeding, failure to thrive, hypotonia, encephalopathy [52], severe mental retardation, unusual facial features, brain malformation, and epileptic seizures [53]. We noted significant reduction in head size and complete loss of cranial ridges in severely deformed reference embryos.

Due to severe morphological abnormalities oberved among reference embryos, it was often difficult to accurately stage the embryos, which likely confounded some of our gene expression analyses. Significant changes in gene expression that corelate with morphology are similar among normal to moderately deformed embryos, while severely deformed embryos show different patterns of gene expression (Figure 3B). Moreover, the gene expression differences become more pronounced between extremely deformed embryos, when compared to both normal to moderately deformed and severely deformed embryos. Importantly, synergistic effects of BNF and ANF were only evident among severely and extremely deformed reference embryos, providing further evidence of PAH-resistance in the Elizabeth River (resistant) embryo population.

\section{Few genes contribute to large phenotypic changes between embryo populations}

Despite the striking differences in embryo morphology between reference and resistant embryos, a relatively low percentage of genes $(2.24 \%$ of 6,764$)$ showed statistically significant differences in transcript levels (Figure 3A). This percentage is less than the percentage of genes significantly differentially expressed between PCB treated embryos from another resistant Fundulus population and a nearby reference site. At 15 days post-fertilization, $2.4 \%$ of genes differ with an FDR p-value of $<0.01$ between embryos from New Bedford Harbor, which are resistant to PCBs, and embryos from a reference population treated with PCBs [57]. Previous results comparing untreated embryos from parents collected from polluted resistant and reference populations also found a surprisingly small number of significantly differently expressed genes (using the same microarray platform, $0.8 \%$ of the genes differed significantly between embryos collected from parents from the Elizabeth River population and nearby reference populations [43]). One possible explanation for this finding was that differences would only manifest in the correct environment (e.g., gene by environment interactions). Given the data presented here, this explanation appears not to be true (at least for the combined treatment of BNF and ANF). Considering the large variation in gene expression reported within and among multiple reference and resistant adult $F$. heteroclitus populations [27,28,58-60], this low percentage of genes whose expression significantly differs between both treated and untreated reference and resistant embryo populations is unexpected.

This small percentage of significantly differentially expressed genes may be due to several factors. Relatively small changes in gene expression not detected by our analysis may be biologically important during late organogenesis. We did not test all of the genes expressed during development, so some of the important gene expression differences were likely missed. Also, some of the significant gene expression differences may be masked by large changes in gene expression that occur between stages during normal Fundulus development [61]. Our analysis was performed on whole embryos, thus potentially masking some tissue-specific gene expression differences. Critical differences in gene expression may occur at earlier or later developmental stages than the one we examined (stage 31, late organogenesis). However, a recent transcriptome comparison of PCBexposed reference and resistant Fundulus embryos at two time-points during embryogenesis [5 and 10 days post fertilization (dpf), approximately stage 28-29, and 35 , respectively] and one larval stage (15 dpf, approximately stage 39-40) revealed a stage-specific response and cumulative pollutant effect reflected by the increase of significantly expressed genes at later stages [57]. Arguably, more robust tissue-specific changes in gene expression occur during early development, particularly during early CNS (stages 16-19) and cardiovascular organogenesis (stages 16-25).

Finally, increasing a relatively small biological sample size per treatment $(\mathrm{N}=4)$ and statistical power in our microarray analysis could have revealed more statistically significant genes. Previous tissue-specific studies on Fundulus adults using only one more individual (five versus four) from these same populations have reported up to $40 \%$ of genes that differ due to treatment (population) [27,58]. However, our recently published study comparing eight resistant and twelve reference, untreated embryos during late organogenesis using the same microarray platform revealed less than $1 \%$ of significant differently expressed genes [43]. Although we identified significant changes in gene expression and correlated them with multiple phenotypes, other factors not considered in our study, such as post-translational modifications and changes in protein expression and enzyme activity are likely contributors to observed differences between resistant and reference embryo populations.

\section{Conclusions}

Our study demonstrates important contrasts in responses between reference and resistant natural embryo populations to synergistic effects of surrogate model PAHs that 
may be important in adaptive mechanisms mediating $\mathrm{PAH}$ effects during fish embryo development. While the reference embryos become severely deformed and none survive ANF/BNF co-exposures, the absence of moderate and severe deformities, lack of significant changes in heart rates and developmental delays, and $>70 \%$ survival among resistant embryos co-exposed with BNF and ANF relative to reference and resistant control embryos clearly demonstrates the resistant embryos' ability to adapt and survive. By analyzing multiple phenotypes and linking them to gene expression patterns of reference and resistant embryos, we provide additional evidence for acquired resistance among embryos whose parents live at heavily contaminated sites: while most treatments caused very little effect on development of resistant embryos, synergistic effects of a PAH-type representative AHR agonist and CYP1A inducer caused developmental delays, impaired cardiac function, morphological alterations, and mortality of reference embryos. These phenotypes mirror embryo responses observed during exposure to complex mixtures of pollutants found in Elizabeth River sediment extracts, but in contrast to exposure to sediment extracts that significantly altered expression of many genes (20\% of 6,551 genes, unpublished data), we found a surprisingly small percentage of significantly differentially expressed genes (2.24\% of 6,764 genes) upon treatment with a mixture of two model PAHs, $\alpha$-napthoflavone and $\beta$-napthoflavone. These results suggest that relatively few genes contribute to the large phenotypic changes seen among reference and resistant populations upon exposure to PAH pollutants.

\section{Methods}

\section{Fish care}

Adult Fundulus were collected from both a reference site at King's Creek, near the mouth of the York River in Gloucester County, Virginia (37¹7'52.4' N, 76²5'31.4"W) and from a contaminated site on the Elizabeth River in Portsmouth, Virginia (36 $\left.48^{\prime} 27.48^{\prime \prime} \mathrm{N}, 7^{\circ} 17^{\prime} 35.77^{\prime \prime} \mathrm{W}\right)$. Adult fish were depurated for 12 months in a recirculating system containing artificial seawater (ASW 25 ppt) prepared from Instant Ocean ${ }^{\circledR}$ (Mentor, OH). Fish were kept at $23-25^{\circ} \mathrm{C}$ on a photoperiod of 14:10 L:D and fed a daily diet of Tetramin ${ }^{\odot}$ Tropical Fish Food (Tetra Systems, Blacksburg VA, USA) and newly hatched brine shrimp (Artemia, Brine Shrimp Direct, Ogden, UT). Killifish embryos were obtained from in vitro fertilization of pooled oocytes mixed with pooled milt from multiple males. Embryos were examined 24 hours post fertilization (hpf) for viability and placed individually into $20 \mathrm{~mL}$ glass scintillation vials with $10 \mathrm{~mL}$ of treatment solution.

\section{Chemicals and exposure}

Dimethyl sulfoxide (DMSO), ANF, BNF and ethoxyresorufin were purchased from Sigma-Aldrich (St. Louis,
MO). King's Creek (reference) embryos and Elizabeth River (sensitive embryos) were exposed to the following treatments:

Treatment 1: DMSO / vehicle (Control)

Treatment 2: $1 \mathrm{ug} / \mathrm{L}$ BNF (BNF)

Treatment 3: $50 \mathrm{ug} / \mathrm{L}$ ANF (low ANF)

Treatment 4: $100 \mathrm{ug} / \mathrm{L}$ ANF (high ANF)

Treatment 5: $1 \mathrm{ug} / \mathrm{L} \mathrm{BNF}+50 \mathrm{ug} / \mathrm{L}$ ANF

(BNF + low ANF)

Treatment 6: $1 \mathrm{ug} / \mathrm{L} \mathrm{BNF}+100 \mathrm{ug} / \mathrm{L}$ ANF

(BNF + high ANF).

Individual embryos of parents from both populations were exposed to the treatment solution or to the DMSO vehicle control from 24 to $120 \mathrm{hpf}(\mathrm{n}=20)$. In all of the treatment groups, DMSO concentration was maintained at less than $0.03 \%$. At $120 \mathrm{hpf}$, embryos were removed from the dosing solution and placed into vials containing clean ASW.

\section{Embryo survival, developmental delays, and heart rate}

Fertilization success and embryo progress were monitored daily by examining representative stages during pre-determined time periods [61,62] using a dissecting stereo microscope (Nikon SME1500, Japan). Stage progression, developmental delays, normal versus abnormal development, and mortality also were recorded. Unfertilized eggs, malformed and/or dead embryos were removed from the population, and times and stages of arrest and abnormal development were recorded accordingly. Survival rates were measured within each treatment in both populations. Embryos that successfully reached stage 31 were used for heart rate and gene expression analysis. Ten embryos from each treatment group were assessed for hatching success and survival to complete embryogenesis, marked with the total yolk consumption by the free-swimming Fundulus [61,62].

To determine developmental delays, ten embryos from each population were monitored in individual $20 \mathrm{ml}$ scintillation vials. Identification of each stage was determined using a dissecting stereo microscope at 70-80X magnification. At approximately 144-150 hpf, when the embryos were expected to reach stage $31[61,62]$, multiple images of developing embryos were captured with the Micropublisher 5.0 RTV Camera (QImaging). These images were catalogued, stored, and analyzed using QCaputre Pro imaging software. Each embryo was scored based on multiple morphological characteristics and assigned the appropriate developmental stage.

The same embryos used to determine developmental delays were used to determine heart rates during early organogenesis (stage 31). A beating heart is formed, with both chambers completely differentiated and in 
full view, by stage 31 and the heart rate can be accurately measured from that stage on. Embryo vials were labeled to assure that the heart rate was measured from the same embryo at both stages. Individual embryos were placed on a depression slide under the dissecting stereo microscope for 1 minute prior to taking heart rate measurements so that the stressed embryo could re-establish resting heart beat (most Fundulus embryos temporarily arrest their heart beat due to a sudden change of environment, such as transfer from the petri dish to a well-lit slide surface). The heart rate of each embryo was measured by counting the number of heartbeats for 30 seconds (preliminary results showed no change in the average heart beat when counts were taken at either 30 second or 1 minute intervals).

\section{Embryo morphology}

At 168 hours-post-fertilization (hpf), ten embryos from each treatment were randomly selected and subjectively scored treatment-blind twice independently $(\mathrm{N}=2)$ for morphological abnormalities using light microscopy. Embryos were scored for severity of heart deformities (tube heart), pericardial edema, hemorrhaging, craniofacial alterations, tail shortening, and pigment loss. Embryo score was based on a 1-5 scale, 1 representing no deformities, 2-mild, 3-moderate, 4-severe, and 5-extreme, respectively. Non-deformed embryos appeared wrapped approximately $2 / 3$ around the full circumference of the remaining yolk, and with clearly distinguishable cranial ridges, well-defined dark-pigmented eyes with visible retinas, dark and scattered body pigment, clearly distinct atrial and ventricular cardiac regions, absence of hemorrhaging, and the caudal region approximately $1 / 3$ of the body length beginning at the bilobed urinary bladder [61]. The most severely affected embryos were characterized by overall smaller size, disproportional size reduction of cranium including diminished distance between eyes, complete loss of cranial ridges, reduction of eye pigmentation, near-complete aggregation and overall reduction of body pigmentation, hemorrhaging along the entire shortened caudal region, and complete loss of cardiac muscle integrity characterized by the absence of heart chambers and formation of a thin-walled, translucent "tube heart".

Results for each treatment were represented as an average of the individual scores.

While all phenotypes were considered in determining the final score, the heart deformities were found to be the most reference and reliable endpoint used in deformity assessment.

These experiments were performed according to approved protocols (Institutional Animal Care and Use Committees, North Carolina State University and Duke University).
Survival, heart rate, developmental delays, and morphology statistical analysis

Differences in the survival, heart rate, developmental delays, and morphology, among two embryo populations and six treatments were analyzed with Prism Statistical Software. Data were normally distributed and were analyzed using one-way Analysis of Variance (1-way ANOVA, $\mathrm{p}<0.05$ ); pairwise $\mathrm{t}$-test was used to test the differences of means between treatment groups, while Dunnett's one-tailed $\mathrm{t}$-test was used to evaluate differences between "reference" embryos and "resistant" embryos, respectively.

\section{Microarrays}

Amplified cDNA sequences for 7,000 genes from $F$. heteroclitus cDNA libraries were spotted onto epoxide slides (Corning) using an inkjet printer (Aj100, ArrayJet, Scotland). Libraries were made from all 40 stages of Fundulus development, immediately post-hatch whole larvae, and adult tissues. Each slide contained four spatially separated arrays of $\sim 7,000$ spots (genes) including controls. Sequence information, annotation and gene ontology are available for Fundulus on the FunnyBase website http:// www.ccs.miami.edu/cgi-bin/Fundulus/Fundulus_home.cgi.

\section{Embryo RNA isolation, amplification, and labeling}

Four individual embryos from each treatment at developmental stage 31 [62] were used for RNA isolation, labeling, and microarray hybridization. Embryo RNA was extracted using a TRIzol buffer (Invitrogen, Carlsbad, CA, USA) followed by purification using the Qiagen RNeasy Mini Kit (Qiagen Inc., Valencia, CA, USA).

Purified RNA was quantified with a spectrophotometer, and RNA quality was assessed by gel electrophoresis. RNA for hybridization was prepared by one round of amplification (aRNA) using Ambion's Amino Allyl MessageAmp aRNA Kit to form copy template RNA by T7 amplification. Amino-allyl UTP was incorporated into targets during $\mathrm{T} 7$ transcription, and resulting amino-allyl aRNA was coupled to Cy3 and Cy5 dyes (GE Healthcare, Piscataway, NJ, USA).

Labeled aRNA samples ( 2 pmol dye/ $\mu \mathrm{l})$ were hybridized to slides in $10 \mu \mathrm{l}$ of hybridization buffer [50\% formamide buffer, $5 \mathrm{x}$ SSPE, $1 \%$ sodium dodecyl sulfate, $0.2 \mathrm{mg} / \mathrm{ml}$ bovine serum albumin, $1 \mathrm{mg} / \mathrm{ml}$ denatured salmon sperm DNA (Sigma), and $1 \mathrm{mg} / \mathrm{ml}$ RNase free poly(A) RNA (Sigma)] for 44 hours at $42^{\circ} \mathrm{C}$. Slides were prepared for hybridization by blocking in $5 \%$ ethanolamine, $100 \mathrm{mM}$ Tris $\mathrm{pH} 7.8$, and $0.1 \%$ SDS added just before use for 30 minutes at room temperature, washed for one hour in $4 \mathrm{xSSC}, 0.1 \% \mathrm{SDS}$ at $50^{\circ} \mathrm{C}$, and then boiled for 2 minutes in distilled water to denature the cDNAs. Resulting 16 bit Tiff Images were quantified using ImaGene (Biodiscovery, Inc.) spotfinding software. Controls and any gene that did not have at 
least one individual with a signal greater than the average signal from all herring sperm control spots (non-specific hybridization signal) plus one standard deviation were removed prior to statistical analysis. In total, 6,754 genes were analyzed.

\section{Experimental design for microarrays}

A loop design (Figure 5) was used for the microarray hybridizations where each sample is hybridized to 2 arrays using both Cy3 and Cy5 labeled fluorophores [63]. The loop consisted of $\mathrm{Cy} 3$ and Cy5 labeled embryo aRNAs from 4 biological samples and six different treatments (T1-T6: control, $1 \mu \mathrm{g} / \mathrm{L}$ BNF, $50 \mu \mathrm{g} / \mathrm{L}$ ANF, $100 \mu \mathrm{g} / \mathrm{L}$ ANF, $1 \mu \mathrm{g} / \mathrm{L}$ BNF $+50 \mu \mathrm{g} / \mathrm{L}$ ANF, $1 \mu \mathrm{g} / \mathrm{L}$ BNF $+100 \mu \mathrm{g} / \mathrm{L}$ ANF). In total, 48 biological samples were hybridized to 24 microarrays. Each array had different combinations of biological samples, so that the most direct comparisons (i.e., $50 \mu \mathrm{g} / \mathrm{L}$ ANF resistant embryo and $50 \mu \mathrm{g} / \mathrm{L}$ reference embryo) are hybridized to the same array. The loop formed was $\mathrm{T} 1 \mathrm{~S} \rightarrow \mathrm{T} 1 \mathrm{R} \rightarrow \mathrm{T} 2 \mathrm{~S} \rightarrow \mathrm{T} 2 \mathrm{R} \rightarrow \mathrm{T} 3 \mathrm{~S} \rightarrow$ $\mathrm{T} 3 \mathrm{R} \rightarrow \mathrm{T} 4 \mathrm{~S} \rightarrow \mathrm{T} 4 \mathrm{R} \rightarrow \mathrm{T} 5 \mathrm{~S} \rightarrow \mathrm{T} 5 \mathrm{R} \rightarrow \mathrm{T} 6 \mathrm{~S} \rightarrow \mathrm{T} 6 \mathrm{R} \rightarrow$
$\mathrm{T} 1 \mathrm{~S} \rightarrow \mathrm{T} 2 \mathrm{~S} \rightarrow \mathrm{T} 3 \mathrm{~S} \rightarrow \mathrm{T} 4 \mathrm{~S} \rightarrow \mathrm{T} 5 \mathrm{~S} \rightarrow \mathrm{T} 6 \mathrm{~S} \rightarrow \mathrm{T} 1 \mathrm{~S} \rightarrow$ $\mathrm{T} 1 \mathrm{R} \rightarrow \mathrm{T} 2 \mathrm{R} \rightarrow \mathrm{T} 3 \mathrm{R} \rightarrow \mathrm{T} 4 \mathrm{R} \rightarrow \mathrm{T} 5 \mathrm{R} \rightarrow \mathrm{T} 6 \mathrm{R}$, where each arrow represents a separate hybridization (array) with the biological sample at the base of the arrow labeled with Cy3 and the biological pool at the head of the arrow labeled with Cy5. T1-6 is treatment, and S and R represent reference and resistant embryos.

\section{Microarrays statistical analysis}

$\log _{2}$ measures of gene expression were normalized using a linear mixed model in SAS (JMP v6.0.0 with a microarray platform beta-version in SAS v9.1.3) to remove the effects of dye (fixed effect) and array (random effect) following a joint regional and spatial Lowess transformation in MAANOVA Version 0.98 .8 for $\mathrm{R}$ to account for both intensity and spatial bias [64].

The model was of the form $y_{i j}=\mu+A_{i}+D_{j}+(A x D)_{i j}+\varepsilon_{i j}$, where, $y_{i j}$ is the signal from the $i^{\text {th }}$ array with dye $j, \mu$ is the sample mean, $A_{i}$ and $D_{j}$ are the overall variation in arrays and dyes $(\mathrm{Cy} 3$ and $\mathrm{Cy} 5),(\mathrm{AxD})_{\mathrm{ij}}$ is the array $\mathrm{x}$ dye interaction and $\varepsilon_{\mathrm{ij}}$ is the stochastic error $[65,66]$.

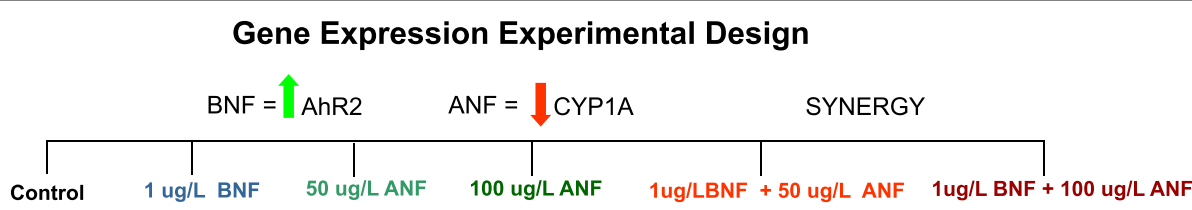

2 Populations $\times 6$ treatments $\times 4$ embryos / population / treatment $=\mathbf{4 8}$ biological samples

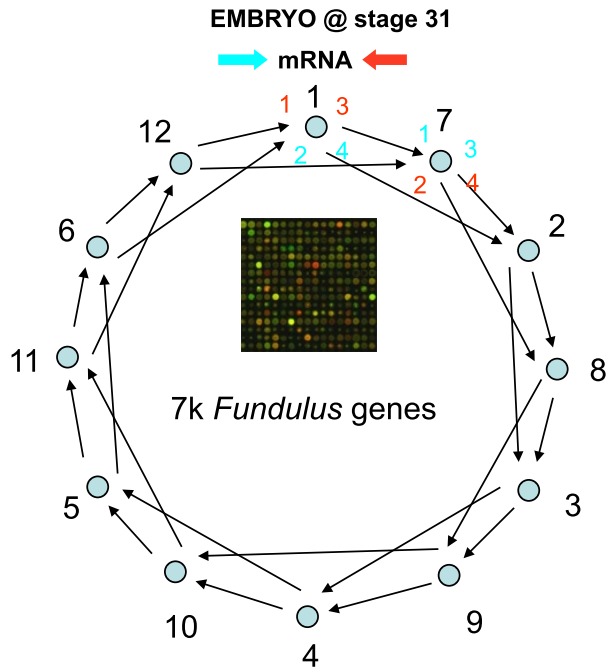

Figure 5 BNF-ANF treatment exposures and microarray loop design: each sample is hybridized to 2 arrays using both Cy3 and Cy5 labeled fluorophores. The loop consisted of Cy3 and Cy5 labeled embryo aRNAs from 4 biological samples and six different treatments (T1-T6: control, $1 \mu \mathrm{g} / \mathrm{L}$ BNF, $50 \mu \mathrm{g} / \mathrm{L}$ ANF, $100 \mu \mathrm{g} / \mathrm{L}$ ANF, $1 \mu \mathrm{g} / \mathrm{L}$ BNF $+50 \mu \mathrm{g} / \mathrm{L}$ ANF, $1 \mu \mathrm{g} / \mathrm{L}$ BNF +100 $\mu \mathrm{g} / \mathrm{L}$ ANF). Anticipated treatment effects on AHR and CYP450IA genes are shown with up and down green/red arrows above the treatments. 48 biological samples were hybridized to 24 microarrays. Each array had different combinations of biological samples, so that the most direct comparisons (i.e., $50 \mu g / L$ ANF resistant embryo and $50 \mu \mathrm{g} / \mathrm{L}$ reference embryo) are hybridized to the same array. The loop formed was T1S $\rightarrow \mathrm{T} 1 \mathrm{R} \rightarrow \mathrm{T} 2 \mathrm{~S} \rightarrow \mathrm{T} 2 \mathrm{R} \rightarrow \mathrm{T} 3 \mathrm{~S} \rightarrow \mathrm{T} 3 \mathrm{R} \rightarrow \mathrm{T} 4 \mathrm{~S} \rightarrow \mathrm{T} 4 \mathrm{R} \rightarrow$ $\mathrm{T} 5 \mathrm{~S} \rightarrow \mathrm{T} 5 \mathrm{R} \rightarrow \mathrm{T} 6 \mathrm{~S} \rightarrow \mathrm{T} 6 \mathrm{R} \rightarrow \mathrm{T} 1 \mathrm{~S} \rightarrow \mathrm{T} 2 \mathrm{~S} \rightarrow \mathrm{T} 3 \mathrm{~S} \rightarrow \mathrm{T} 4 \mathrm{~S} \rightarrow \mathrm{T} 5 \mathrm{~S} \rightarrow \mathrm{T} 6 \mathrm{~S} \rightarrow \mathrm{T} 1 \mathrm{~S} \rightarrow \mathrm{T} 1 \mathrm{R} \rightarrow \mathrm{T} 2 \mathrm{R} \rightarrow \mathrm{T} 3 \mathrm{R} \rightarrow \mathrm{T} 4 \mathrm{R} \rightarrow \mathrm{T} 5 \mathrm{R} \rightarrow \mathrm{T} 6 \mathrm{R}$, where each arrow represents a separate hybridization (array) with the biological sample at the base of the arrow labeled with Cy3 and the biological pool at the head of the arrow labeled with Cy5. T1-6 is treatment, and S and R represent reference and resistant embryos, respectively. A shorter example of the loop design shows treatments as numbers, and arrows as separate hybridization (array). 
Residuals from the above model were used for geneby-gene analyses of treatment effect during a particular developmental stage, using treatment, population $\mathrm{x}$ treatment, and dye as fixed effects, and array and spot nested in array as random effects. The model was $r_{i j k n n}=\mu+A_{i}+$ $\mathrm{D}_{\mathrm{j}}+\mathrm{T}_{\mathrm{k}}+\mathrm{P}_{\mathrm{n}}+(\mathrm{TxP})_{\mathrm{nk}}+\varepsilon_{\mathrm{ijkn}}$ where $T k$ is the $k^{\mathrm{th}}$ treatment (treatments 1-6, above), $P_{n}$ is the $n^{\text {th }}$ population (reference or resistant), and $(\mathrm{TxP})_{\mathrm{nk}}$ is the treatment by population interaction. We also used residuals for a gene-by-gene analysis of morphology: $r_{i j k}=\mu+A_{i}+D_{j}+$ $\mathrm{M}_{\mathrm{k}}+\varepsilon_{\mathrm{ijk}}$ where $M k$ is the $k^{\text {th }}$ morphology (morphology score $1-5$ where 1 is normal and 5 is extremely deformed).

For all mixed model analyses, we used a nominal $\mathrm{p}$-value cut-off for significant genes of $\mathrm{p}<0.01$. Using this $\mathrm{p}$-value reveals more genes that may be differentially expressed but risks identifying genes that may be false positives.

Hierarchical clustering used JmpGenomics, Cluster 3.0 for Mac OS X, and Java TreeView version 1.0.8 [67].

\section{Data accessibility}

Microarray data have been deposited in NCBI's Gene Expression Omnibus (Edgar and Lash, 2002) and are accessible through GEO Series accession number GSE47654.

\section{Competing interests}

The authors declare that they have no competing interests.

\section{Authors' contributions}

$G B, R D, L W$ and MFO designed the experiment. GB and LW performed embryo exposures and developmental and morphological analysis. GB and TLS isolated and labeled embryo RNAs. GB and MFO performed hybridizations and statistical analyses of gene expression data and drafted the manuscript. All authors critically revised the manuscript and gave approval of the final version.

\section{Acknowledgements}

This work was supported by National Institute of Health grants R01 ES011588 and P42 ES007381 to MFO and 2P42 ES010356 to MFO and RD. The funders had no role in study design, data collection and analysis, decision to publish, or preparation of the manuscript. We thank Douglas L. Crawford for critical discussions and comments on the manuscript and for help printing microarrays.

\section{Author details}

'Department of Environmental and Molecular Toxicology, North Carolina State University, Box 7633, Raleigh, NC 27695-7633, USA. '2 Department of Plant Pathology, North Carolina State University, Box 7342, Raleigh, NC 27695-7342, USA. ${ }^{3}$ Nicholas School of the Environment, Duke University, A333 LSRC, Box 90328, Durham, NC 27708, USA. ${ }^{4}$ Rosenstiel School of Marine and Atmospheric Sciences, University of Miami, 4600 Rickenbacker Causeway, Miami, FL 33149, USA. ${ }^{5}$ Current Address: Division of Biological Sciences, University of California at San Diego, HSS 1145G, 9500 Gilman Drive, La Jolla, CA 92093, USA.

Received: 5 July 2013 Accepted: 26 October 2013

Published: 11 November 2013

\section{References}

1. Williams LM, Oleksiak MF: Signatures of selection in natural populations adapted to chronic pollution. BMC Evol Biol 2008, 8:282.
2. Elskus AA, Monosson E, McElroy AE, Stageman JJ, Woltering DS: Altered CYP1A expression in Fundulus heteroclitus adults and larvae: a sign of pollutant resistance? Aquat Toxicol 1999, 45(2-3):99-113.

3. Meyer JN, Smith JD, Winston GW, Di Giulio RT: Antioxidant defenses in killifish (Fundulus heteroclitus) exposed to contaminated sediments and model prooxidants: short-term and heritable responses. Aquat Toxicol 2003, 65(4):377-395.

4. Nacci DE, Coiro L, Champlin D, Jayaraman S, Mckinney R, Gleason TR, Munns JWR, Specker JL, Cooper KR: Adaptation of wild populations of the estuarine fish Fundulus heteroclitus to persistant environmental contaminants. Mar Biol 1999, 134:9-17.

5. Prince R, Cooper KR: Comparison of the effect of 2,3,7,8-tetrachlorodibenzop-dioxin on chemically impacted and nonimpacted subpopulations of Fundulus heteroclitus: II Metabolic Considerations. Environ Toxicol Chem 1995, 14:589-595.

6. Meyer JN, Nacci DE, Di Giulio RT: Cytochrome P4501A (CYP1A) in killifish (Fundulus heteroclitus): heritability of altered expression and relationship to survival in contaminated sediments. Toxicol Sci 2002, 68(1):69-81.

7. Ownby DR, Newman MC, Mulvey M, Vogelbein WK, Unger MA, Arzayus LF: Fish (Fundulus heteroclitus) populations with different exposure histories differ in tolerance of creosote-contaminated sediments. Environ Toxicol Chem 2002, 21(9):1897-1902.

8. Vogelbein WK, Fournie JW, Van Veld PA, Huggett RJ: Hepatic neoplasms in the mummichog Fundulus heteroclitus from a creosote-contaminated site. Cancer Res 1990, 50(18):5978-5986.

9. ATSDR: http://www.atsdr.cdc.gov/cercla/index.html. 2003.

10. ATSDR: www.atsdr.cdc.gov/spl/previous/07list.html. 2007.

11. Barron MG, Heintz R, Rice SD: Relative potency of PAHs and heterocycles as aryl hydrocarbon receptor agonists in fish. Mar Environ Res 2004, 58(2-5):95-100.

12. Wassenberg DM, Di Giulio RT: Synergistic embryotoxicity of polycyclic aromatic hydrocarbon aryl hydrocarbon receptor agonists with cytochrome P4501A inhibitors in Fundulus heteroclitus. Environ Health Perspect 2004, 112(17):1658-1664.

13. Vogelbein WK, Unger M, Gauthier D: The Elizabeth River monitoring program 2007-2007: association between mummichog liver histopahtology and sediment chemical contamination. Quality: Virginia Department of Environmental; 2008.

14. Walker SE, Dickhut RM, Chisholm-Brause C: Polycyclic aromatic hydrocarbons in a highly industrialized urban estuary: inventories and trends. Environ Toxicol Chem 2004, 23(11):2655-2664.

15. Billiard SM, Timme-Laragy AR, Wassenberg DM, Cockman C, Di Giulio RT: The role of the aryl hydrocarbon receptor pathway in mediating synergistic developmental toxicity of polycyclic aromatic hydrocarbons to zebrafish. Toxicol Sci 2006, 92(2):526-536.

16. Meyer JN, Di Giulio RT: Heritable adaptations and fitness cost in killifish (Fundulus heteroclitus) inhabiting a polluted estuary. Ecol Appl 2003, 13(2):490-503.

17. Wassenberg DM, Nerlinger AL, Battle LP, Di Giulio RT: Effects of the polycyclic aromatic hydrocarbon heterocycles, carbazole and dibenzothiophene, on in vivo and in vitro CYP1A activity and polycyclic aromatic hydrocarbon-derived embryonic deformities. Environ Toxicol Chem 2005, 24:2526-2532.

18. Wirgin I, Waldman JR: Resistance to contaminants in North American fish populations. Mutat Res 2004, 552(1-2):73-100

19. Andreasen EA, Spitsbergen JM, Tanguay RL, Stegeman JJ, Heideman W, Peterson RE: Tissue-specific expression of AHR2, ARNT2, and CYP1A in zebrafish embryos and larvae: effects of developmental stage and 2,3,7,8-tetrachlorodibenzo-p-dioxin exposure. Toxicol Sci 2002, 68(2):403-419.

20. Evans BR, Karchner SI, Franks DG, Hahn ME: Duplicate aryl hydrocarbon receptor repressor genes (ahrr1 and ahrr2) in the zebrafish Danio rerio: structure, function, evolution, and AHR-dependent regulation in vivo. Arch Biochem Biophys 2005, 441(2):151-167.

21. Incardona JP, Collier TK, Scholz NL: Defects in cardiac function precede morphological abnormalities in fish embryos exposed to polycyclic aromatic hydrocarbons. Toxicol Appl Pharmacol 2004, 196(2):191-205.

22. Timme-Laragy AR, Cockman CJ, Matson CW, Di Giulio RT: Synergistic induction of AHR regulated genes in developmental toxicity from co-exposure to two model PAHs in zebrafish. Aquat Toxicol 2007, 85(4):241-250. 
23. Billiard SM, Bols NC, Hodson PV: In vitro and in vivo comparisons of fishspecific CYP1A induction relative potency factors for selected polycyclic aromatic hydrocarbons. Ecotoxicol Environ Saf 2004, 59(3):292-299.

24. Goujon FM, Nebert DW, Gielen JE: Genetic expression of aryl hydrocarbon hydroxylase induction. IV. Interaction of various compounds with different forms of cytochrome P-450 and the effect on benzo(a)pyrene metabolism in vitro. Mol Pharmacol 1972, 6:667-680

25. Miranda CL, Henderson MC, Buhler DR: Evaluation of chemicals as inhibitors of trout cytochrome P450s. Toxicol Appl Pharmacol 1998, 148(2):237-244.

26. Testa $B$, Jenner $P$ : Inhibitors of Cytochrome $P-450 \mathrm{~s}$ and their mechanism of action. Drug Metab Rev 1981, 12(1):1-117.

27. Oleksiak MF: Changes in gene expression due to chronic exposure to environmental pollutants. Aquat Toxicol 2008, 90(3):161-171.

28. Weis $P$, Weis JS: Methylmercury teratogenesis in the killifish, Fundulus heteroclitus. Teratology 1977, 16(3):317-325.

29. Whitehead A, Crawford DL: Neutral and adaptive variation in gene expression. Proc Natl Acad Sci U S A 2006, 103(14):5425-5430.

30. Whitehead A, Galvez F, Zhang S, Williams LM, Oleksiak MF: Functional genomics of physiological plasticity and local adaptation in killifish. J Hered 2011, 102(5):499-511.

31. McMillan AM, Bagley MJ, Jackson SA, Nacci DE: Genetic diversity and structure of an estuarine fish (Fundulus heteroclitus) indigenous to sites associated with a highly contaminated urban harbor. Ecotoxicology 2006 , 15(6):539-548

32. Mulvey M, Newman MC, Vogelbein WK, Unger MA, Ownby DR: Genetic structure and mtDNA diversity of Fundulus heteroclitus populations from polycyclic aromatic hydrocarbon-contaminated sites. Environ Toxicol Chem 2003, 22(3):671-677.

33. Roark SA, Kelble MA, Nacci D, Champlin D, Coiro L, Guttman SI: Population genetic structure and tolerance to dioxin-like compounds of a migratory marine fish (Menidia menidia) at polychlorinated biphenyl-contaminated and reference sites. Environ Toxicol Chem 2005, 24(3):726-732.

34. Roark SA, Nacci D, Coiro L, Champlin D, Guttman SI: Population genetic structure of a nonmigratory estuarine fish (Fundulus heteroclitus) across a strong gradient of polychlorinated biphenyl contamination. Environ Toxicol Chem 2005, 24(3):717-725

35. Williams LM, Oleksiak MF: Ecologically and evolutionarily important SNPs identified in natural populations. Mol Biol Evol 2011, 28(6):1817-1826

36. Williams LM, Oleksiak MF: Evolutionary and functional analyses of cytochrome P4501A promoter polymorphisms in natural populations. Mol Ecol 2011, 24:5236-5247.

37. Bickham JW, Sandhu S, Hebert PD, Chikhi L, Athwal R: Effects of chemical contaminants on genetic diversity in natural populations: implications for biomonitoring and ecotoxicology. Mutat Res 2000, 463(1):33-51.

38. Smith GM, Weis SJ: Predator-prey relationships in mumischogs (fundulus heteroclitus): effects of living in a polluted environment. J Exp Mar Biol Ecol 1997, 209(1-2):75-87.

39. Weis JS, Smith GM, Zhou T: Altered predator/pray behavior in polluted environments: implications for conservation. Environ Biol Fishes 1999 55(1-2):43-51.

40. Weis JS, Weis P: Effects of environmental pollutants on early fish development. Rev Aquat Sci 1989, 1:45-73.

41. Coustau C, Chevillon C, Ffrench Constant R: Resistance to xenobiotics and parasites: can we count the cost? Trends Ecol Evo 2000, 15(9):378-383.

42. Rifkin SA, Kim J, White KP: Evolution of gene expression in the Drosophila melanogaster subgroup. Nat Genet 2003, 33(2):138-144.

43. Bozinovic G, Oleksiak MF: Embryonic gene expression among pollutant resistant and sensitive Fundulus heteroclitus populations. Aquat Toxicol 2010, 98(3):221-229.

44. Atkinson KR, Blumenstein M, Black MA, Wu SH, Kasabov N, Taylor RS, Cooper GJ, North RA: An altered pattern of circulating apolipoprotein E3 isoforms is implicated in preeclampsia. J Lipid Res 2009, 50(1):71-80.

45. Hojnik M, George J, Ziporen L, Shoenfeld Y: Heart valve involvement (Libman-Sacks endocarditis) in the antiphospholipid syndrome. Circulation 1996, 93(8):1579-1587.

46. Das AM: Regulation of the mitochondrial ATP-synthase in health and disease. Mol Genet Metab 2003, 79(2):71-82.

47. Akiba Y, Suzuki R, Saito-Saino S, Owada Y, Sakagami H, Watanabe M, Kondo $\mathrm{H}$ : Localization of mRNAs for phosphatidylinositol phosphate kinases in the mouse brain during development. Brain Res Gene Expr Patterns 2002, 1(2):123-133.

48. Seidel U, Bober E, Winter B, Lenz S, Lohse P, Goedde HW, Grzeschik KH, Arnold $\mathrm{HH}$ : Alkali myosin light chains in man are encoded by a multigene family that includes the adult skeletal muscle, the embryonic or atrial, and nonsarcomeric isoforms. Gene 1988, 66(1):135-146.

49. Chen Z, Huang W, Dahme T, Rottbauer W, Ackerman MJ, Xu X: Depletion of zebrafish essential and regulatory myosin light chains reduces cardiac function through distinct mechanisms. Cardiovasc Res 2008, 79(1):97-108.

50. Grover GJ, Marone PA, Koetzner L, Seto-Young D: Energetic signalling in the control of mitochondrial F1F0 ATP synthase activity in health and disease. Int J Biochem Cell Biol 2008, 40(12):2698-2701.

51. Frederick JP, Mattiske D, Wofford JA, Megosh LC, Drake LY, Chiou ST, Hogan BL, York JD: An essential role for an inositol polyphosphate multikinase, Ipk2, in mouse embryogenesis and second messenger production. Proc Natl Acad Sci U S A 2005, 102(24):8454-8459.

52. Bayley JP, Launonen V, Tomlinson IP: The FH mutation database: an online database of fumarate hydratase mutations involved in the MCUL (HLRCC) tumor syndrome and congenital fumarase deficiency. BMC Med Genet 2008, 9:20

53. Kerrigan JF, Aleck KA, Tarby TJ, Bird CR, Heidenreich RA: Fumaric aciduria: clinical and imaging features. Ann Neurol 2000, 47(5):583-588.

54. Marin-Garcia J, Goldenthal MJ: Mitochondrial centrality in heart failure. Heart Fail Rev 2008, 13(2):137-150.

55. Murray AJ, Edwards LM, Clarke K: Mitochondria and heart failure. Curr Opin Clin Nutr Metab Care 2007, 10(6):704-711.

56. Edwards $\mathrm{YH}$, Hopkinson DA: The genetic determination of fumarase isozymes in human tissues. Ann Hum Genet 1979, 42(3):303-313.

57. Oleksiak MF, Karchner SI, Jenny MJ, Franks DG, Welch DB, Hahn ME: Transcriptomic assessment of resistance to effects of an aryl hydrocarbon receptor (AHR) agonist in embryos of Atlantic killifish (Fundulus heteroclitus) from a marine Superfund site. BMC Genomics 2011, 12:263.

58. Fisher MA, Oleksiak MF: Convergence and divergence in gene expression among natural populations exposed to pollution. BMC Genomics 2007 8:108

59. Oleksiak MF, Roach JL, Crawford DL: Natural variation in cardiac metabolism and gene expression in Fundulus heteroclitus. Nat Genet 2005, 37(1):67-72.

60. Oleksiak MF, Churchill GA, Crawford DL: Variation in gene expression within and among natural populations. Nat Genet 2002, 32(2):261-266.

61. Bozinovic G, Sit TL, Hinton DE, Oleksiak MF: Gene expression throughout a vertebrate's embryogenesis. BMC Genomics 2011, 12:132.

62. Armstrong PB, Child JS: Stages of normal development of Fundulus heteroclitus. Biol Bull 1965, 128(2):143-168.

63. Kerr K, Churchill G: Experimental design for gene expression analysis. Biostatistics 2001, 2:183-201.

64. Wu H, Kerr K, Cui X, Churchill G: "MAANOVA: a software package for the analysis of spotted CDNA microarray experiments". The Analysis of Gene Expression Data: Methods and Software. Springer New York; 2003:313-341.

65. Jin W, Riley RM, Wolfinger RD, White KP, Passador-Gurgel G, Gibson G: The contributions of sex, genotype and age to transcriptional variance in Drosophila melanogaster. Nat Genet 2001, 29(4):389-395.

66. Wolfinger RD, Gibson G, Wolfinger ED, Bennett L, Hamadeh $H$, Bushel $P$, Afshari C, Paules RS: Assessing gene significance from CDNA microarray expression data via mixed models. J Comput Biol 2001, 8(6):625-637.

67. de Hoon MJ, Imoto S, Nolan J, Miyano S: Open source clustering software. Bioinformatics 2004, 20(9):1453-1454.

\section{doi:10.1186/1471-2164-14-779}

Cite this article as: Bozinovic et al.: Genomic and physiological responses to strong selective pressure during late organogenesis: few gene expression changes found despite striking morphological differences. BMC Genomics 2013 14:779. 